\title{
Atlantic tropical cyclogenetic processes during SOP-3 NAMMA in the GEOS-5 global data assimilation and forecast system.
}

\author{
Oreste Reale* \\ $\dagger$ \\ William K. Lau \\ Kyu-Myong Kim \\ Eugenia Brin \\ $\S$ \\ Laboratory for Atmospheres \\ NASA Goddard Space Flight Center \\ Greenbelt, Maryland 20771
}

February 27, 2009

\footnotetext{
*Email Oreste.Reale-1@nasa.gov

${ }^{\dagger}$ Additional Affiliation: University of Maryland, Baltimore County, Baltimore, Maryland

¥Additional Affiliation: University of Maryland, Baltimore County, Baltimore, Maryland

${ }^{\S}$ Science Applications International Corporation, Beltsville, Maryland
} 
This article investigates the role of the Saharan Air Layer (SAL) in tropical cyclogenetic processes associated with a non-developing and a developing African easterly wave observed during the Special Observation Period (SOP-3) phase of the 2006 NASA African Monsoon Multidisciplinary Analyses (NAMMA). The two waves are chosen because both interact heavily with Saharan air. A global data assimilation and forecast system, the NASA GEOS-5, is being run to produce a set of high-quality global analyses, inclusive of all observations used operationally but with denser satellite information. In particular, following previous works by the same Authors, the quality-controlled data from the Atmospheric Infrared Sounder (AIRS) used to produce these analyses have a better coverage than the one adopted by operational centers. From these improved analyses, two sets of 31 5-day high resolution forecasts, at horizontal resolutions of both half and quarter degrees, are produced. Results show that very steep moisture gradients are associated with the SAL in forecasts and analyses even at great distance from the Sahara. In addition, a thermal dipole (warm above, cool below) is present in the non-developing case. Moderate Resolution Imaging Spectroradiometer (MODIS) show that aerosol optical thickness is higher in the non-developing case. Altogether, results suggest that radiative effect of dust may play some role in producing a thermal structure less favorable to cyclogenesis. Results also indicate that only global horizontal resolutions on the order of 20-30 kilometers can capture the large-scale transport and the fine thermal structure of the SAL, inclusive of the sharp moisture gradients, reproducing the effect of tropical cyclone suppression which has been hypothesized by previous authors from observational and regional 
modeling perspectives. These effects cannot be fully represented at lower resolutions. Global resolution of a quarter of a degree is a minimum critical threshold to investigate Atlantic tropical cyclogenesis from a global modeling perspective. 


\section{Introduction}

African Easterly Waves (AEWs) have been recognized as prominent weatherproducing events of northern tropical Africa (e.g Burpee 1974; Asnani 2005) and have been extensively studied from observational and modeling perspectives (e.g Hsieh and Cook 2005; Kiladis et al. 2006). However, the development of AEWs into tropical depressions remains one of the most challenging problems in the prediction and modeling of Atlantic tropical cyclones.

Investigations of tropical cyclogenesis have been generally carried out from either strictly observational or high-resolution mesoscale points of view, because the lower resolution used in most global models is deemed to be inadequate to trigger spontaneous cyclogenesis. However, in recent years a number of global models have reached the resolution of $10-40 \mathrm{~km}$ and have started to display some tropical cyclogenesis capability. Atlas et al. (2005) shown that a semi-operational version of the model being run at NASA at that time was capable of producing well-defined tropical cyclone structures even if initialized with low-resolution analyses in which cyclones were either not present or analyzed properly. Shen et al. (2006) used a higher resolution research version of the same model producing center pressures on the order of $920 \mathrm{hPa}$ for hurricane Katrina; Reale et al. (2007) analyzed the performance of the European Center for Medium Range Weather Forecasts (ECMWF) so-called Nature Run (a 13-month long simulation in free running mode performed with the then-operational ECMWF model) and verified that the simulation contained realistic AEW activity and a realistic number of At- 
lantic tropical cyclones.

Strictly speaking, the resolutions adopted by the above referenced studies cannot be considered adequate yet to resolve the fine structure of tropical cyclogenetic processes, because the organization of several convective centers into a rotating system requires cloud-resolving resolutions which are not yet possible in realtime global numerical weather prediction models. Despite these limitations, it is nonetheless remarkable that the aforementioned high-resolution global models, with different experimental or operational configurations, display distinct cyclogenetic capabilities.

Moreover, it is important to emphasize that the processes of cyclogenesis and cyclogenesis suppression should be studied from different perspectives, and global models do have the unquestionable advantages of 1) better capturing the largescale forcings involved, and 2) not relying upon somewhat questionable boundary conditions imposed on the domain's boundaries of limited area models.

Among the large-scale problems connected with tropical cyclogenesis, one of the most debated is perhaps the role of the Saharan Air Layer (SAL). The SAL, a layer of hot dry air rich in dust and produced over the Sahara Desert (Carlson and Prospero 1972), has been subject to intense scrutiny in order to understand its possible connection with tropical cyclone development or suppression.

Dunion and Velden (2004) investigate the SAL with the aid of Geostationary Operational Environmental Satellite (GOES) and recognize it as a possible mechanism linked to tropical cyclone suppression, emphasizing three possible cyclogenesis inhibiting actions: increased static stability, increased vertical shear and dry 
air inclusion. On a longer temporal scale, Lau and Kim (2007) present evidence on that the mean activity of the SAL is likely to impact the large-scale environment, including sea-surface temperature (SST) and mean vertical shear, during the entire hurricane season.

However, Jenkins and Pratt (2008) have investigated the connection between dust, observed lightning and tropical cyclones during NAMMA-06, with emphasis on mycrophysical processes, confirming that SAL increases static stability and may reduce SST, but also suggesting that SAL may invigorate rain bands connected with cyclogenesis, and can also increase cyclonic vorticity of AEWs. In the subsequent paper by the same first Author, Jenkins et al. (2008) present more evidence of a possible tropical cyclone rain band invigoration due to Saharan dust.

At this time, it appears that there is no conclusive evidence on a clear, unambiguous role of the SAL with respect to cyclogenesis, and the only certain fact is the extreme complexity of the interaction between the SAL and tropical weather systems, which requires much more research.

In this paper, it is shown that a high resolution global data assimilation system (DAS) coupled with a global model of comparable or even higher resolution are suitable tools to investigate the role of the SAL not only on the wave scale, but also from the point of view of the large-scale transport from its source region, and can therefore represent the possible modifications of SAL as the waves propagate over thousands of kilometers.

At the same time, it is shown that model horizontal resolution not lower than a quarter of a degree is needed to unveil some of the SAL thermodynamic and 
kinematic features, such as the increasingly narrow structure of the dry air filaments being intruded in a tropical circulation, and the sharpness of the boundaries between Saharan and non-Saharan air.

In this work, we explore processes associated with two waves which were observed during the Special Observing Phase (SOP-3) of NAMMA, with the aid of the global data assimilation and forecasting system called NASA GEOS-5. Of particular concern for this article is the representation of the thermal structure during cyclogenesis, and in particular the possible role of SAL. Section 2 describes the data assimilation, computational aspects and simulations performed, Section 3 analyzes the results, Section 4 presents a general discussion and Section 5 states the conclusion of this work.

\section{The NASA GEOS-5 Data Assimilation and Fore- casting System}

The effect of Saharan air on Atlantic tropical cyclogenesis is investigated using a high-resolution global DAS based upon the Gridpoint Statistical Interpolation (GSI) analysis algorithm co-developed by the National Centers for Environmental Predictions (NCEP) Environmental Modeling Center, documented in Wu et al. (2002). The NASA GEOS-5 combines the above referenced DAS with the NASA atmospheric global forecast model documented in Bosilovich et al. (2006) and used, among others, by Reale et al. (2008) and Reale et al. (2009). The forecast model shares the same dynamical core (Lin, 2004) with the so-called NASA finite-volume General Circulation Model (fvGCM) which, in the version known 
as GEOS-4, demonstrated remarkable capabilities in hurricane forecasting (Atlas et al., 2005; Shen et al., 2006).

The GEOS-5 however contains a new physics (convective and boundary layer parametrizations), developed predominantly by the Global Modeling and Assimilation Office (GMAO). The changes in physics made the system quite different from its predecessor. From one side global forecasting skill has substantially increased, with the performance of the model becoming comparable to major operational centers (e.g. Reale et al. 2008). Moreover, the heavy reliance on satellite data has made the performance quite symmetric between the two hemispheres, unlike many operational models which rely more on conventional observations and consequently display a substantial difference in performance between the northern and the southern Hemisphere. However, the capability of representing very deep tropical cyclones, which was remarkable in the previous versions (Atlas et al. 2005; Shen et al. 2006) seem to have disappeared in the current configuration, possibly because of a different convection parametrization adopted.

However, the most important difference between the GEOS-5 and the system used in these two previous studies is in the initialization. Both Atlas et al. (2005) and Shen et al. (2006), despite running the model at horizontal resolutions of $0.25^{\circ}$ and $0.125^{\circ}$ respectively, used initial conditions at about $1^{\circ}$ resolution obtained from the NCEP operational analyses. On the other contrary, this study makes full use of the data assimilation system included in the GEOS-5, and produces its own set of global, high-resolution $0.5^{\circ}$, high-quality analyses. The analyses contain all the operational data used by NCEP at that time, but a much 
denser satellite information. In particular, a much improved coverage from the Atmospheric Infrared Sounder (AIRS) is utilized, as compared to the one used by operational forecasts. Instead of clear-sky AIRS radiances, which make use of AIRS data only from channels completely unaffected by clouds, we use qualitycontrolled temperature retrievals obtained also under partly cloudy conditions, following Susskind et al. (2006) and Susskind (2007). Despite the widespread general assumption that clear-sky radiances are the best way to assimilate AIRS data, Reale et al (2009) have shown retrievals under partial cloudy conditions to provide better analyses of a tropical cyclone in the Indian ocean than the clear-sky radiance methodology. Finally it should be stressed that the DAS for this experiment is configured without any bogus vortex or vortex relocation technique. As a consequence, tropical development, if any, is spontaneously produced by the model.

One 35-day global data assimilation, starting at 00z 13 August 2006, is performed with the GEOS-5 DAS, to cover the entire period of the SOP-3 phase of the NAMMA campaign. From the analyses, two sets of 31 five-day forecasts, at two different resolutions, are performed. The DAS and forecast model configuration is the same used by Reale et al. (2008) but at higher resolution: the DAS is being run at a horizontal resolution of $0.67^{\circ} \times 0.5^{\circ}$ and the forecast model is run at and $0.25^{\circ} \times 0.33^{\circ}$ and $0.67^{\circ} \times 0.5^{\circ}$, both with 72 vertical levels.

Analyses and forecasts are validated and verified against operational NCEP analyses. The analyses correspond remarkably well to the operational NCEP analyses, as it will shown later, but with more information available, due to higher 
resolution and possibly denser satellite information assimilated. Global and hemispheric forecast skills, investigated through the anomaly correlation for $500 \mathrm{hPa}$ geopotential as a function of forecast time, range from approximately 0.76 to 0.80 at day 5 (not shown), indicating that the forecast skill for boreal summer conditions is reasonable, and comparable to the slightly superior forecast skill obtained for boreal winter conditions (Reale et al. 2008).

\section{Analysis and Simulation}

\section{3a. Validation}

In this work we focus on two events of the SOP-3: one non-developing and one developing AEW, appearing quite similar in terms of the intensity of the low-level circulation, vertical shear and other dynamical forcings, and we investigate their different evolution and the different properties of the corresponding SAL intrusions. Figure 1 shows a Hovmøller diagram of $700 \mathrm{hPa}$ relative vorticity and relative humidity obtained from the GEOS-5 analyses, to emphasize AEWs observed during the SOP-3, covering the second half of August. From Fig. 1, left panel, the strongest wave of the period appears on 23 August at about $5^{\circ} \mathrm{W}$, undergoing transition from continental to oceanic environment on the following day (hereafter W1). An evident sharp strip of dry air shows the same propagation speed and amplitude of the wave and is clearly associated with a Saharan Air outbreak which shortly precedes the wave. There is a hint of another SAL outbreak appearing on Fig. 1 at about $20^{\circ} \mathrm{W}$ and lagging of about 1 day, but this is not fully captured here because the outbreak occurs at higher latitude. 
In Figure 2 the same Hovmøller diagram is extracted from operational NCEP analyses (interpolated on pressure levels at $1^{\circ} \times 1^{\circ}$ ), for validation purposes. There is a very good correspondence in the vorticity fields, except that the GEOS-5 analyses show a higher amount of detail, due to the higher resolution. As for the moisture, it is intrinsically a very noisy field, but the correspondence between the basic features is very good.

To further confirm the legitimacy of our analyses, we also use NAMMA data for validation. In Figure 3, the profiles of the zonal and meridional wind components, obtained from the vertical grand-based soundings from the Cape Verde Islands, at $14.926111 \mathrm{~N}, 23.494611 \mathrm{~W}$ and an altitude of $85 \mathrm{~m}$, are reported (radiosonde data are available online at: http://namma.msfc.nasa.gov). The zonal wind time-series clearly shows the African Easterly Jet (AEJ) located between $700 \mathrm{hPa}$ and $600 \mathrm{hPa}$ with its amplited being modulated at time scale of two to seven days. The weakening of the AEJ is associated with the passage of waves, shown as sign inversions in the meridional wind time-series. The northerly to southerly change occurred at Aug 26 coincide with the passage of the positive vorticity over Cape Verde Islands shown in Figures 1 and 2.

In Figure 4, zonal and meridional wind profiles extracted at the same coordinates from the GEOS-5 analyses are provided. Despite that the two data sets are not strictly comparable, (the GEOS-5 sequence of profiles is computed continuously every 6 hours, whereas the plot in Figure 3 is an interpolation of daily profiles), the GEOS-5 analyses match very well with the observed data: the four episodes of maximum zonal wind on 19-21 Aug, 22Aug, 1-3 September, 5-7 
September, and 11-13 September correspond perfectly to the observations. The height of the maximum wind is at about $600 \mathrm{hPa}$, exactly as in the observed profiles and, most important, even the maximum values of zonal wind are comparable, being on the order of $20 \mathrm{~m} \mathrm{~s}^{-1}$.

Also a comparison of the meridional component reveal that the major wave passages are captured: the positive values of $\mathrm{v}$, corresponding to northerly component (23 August, 27 August, 4 September, and 13 September) on the order of $5-15 m s^{-1}$, indicating a wave passage, and present in Figure 3, are clearly reproduced in the GEOS-5 high resolution analyses.

\section{3b. Nondeveloping wave}

With the strong confidence provided by the good quality of the GEOS-5 analyses, we investigate the structure and kinematics of the major nondeveloping wave observed in the first part of the campaign.

In Figure 5, $700 \mathrm{hPa}$ specific humidity and $900 \mathrm{hPa}$ flow are shown together to emphasize the relationship between two different levels in the analysis $(00 \mathrm{z} 26$ August) and across 3 forecast times (24, 48 and 72 hour forecast, corresponding to verification times of $00 \mathrm{z} 27,28$ and 29 August respectively). The 700hPa and $900 \mathrm{hPa}$ levels correspond approximately to the vertical center and the base of the SAL, with the latter emphasizing the low-level circulation. Despite the strength of the wave, and the short-lasting apparent formation of a vertically aligned circulation evident in the analyses from lower levels up to almost 500hPa (not shown), W1 becomes a nondeveloping wave. Figure 5 shows that dry air at $700 \mathrm{hPa}$, 
present at $00 \mathrm{Z} 26 \mathrm{Aug}$ to the west of the $900 \mathrm{hPa}$ circulation center (at about $17^{\circ} \mathrm{N} ; 21^{\circ} \mathrm{W}$ ), is being advected in 24 hours on the top of it (about $30^{\circ} \mathrm{W}$ ). After that, the rotating system becomes elongated and then rapidly evolves into an open wave (48 and 72 forecasts). This is even more evident while analyzing intermediate time-steps (not shown).

In Figure 6, a zonal vertical cross-section of specific humidity at $20^{\circ} \mathrm{N}$ is extracted from the GEOS-5 24-hour forecast (displayed in Fig 5), intersecting the SAL outbreak between $40^{\circ} \mathrm{W}$ and $35^{\circ} \mathrm{W}$. The signature of the SAL as a sharply defined 'corridor' of extremely dry air centered at about $38^{\circ} \mathrm{W}$ (with values less $2 g K^{-1}$, surrounded by values larger than $8 g K^{-1}$ ) can be seen down to $800 \mathrm{hPa}$. Remarkable moisture gradients are present on both sides. A zonal temperature anomaly is obtained by subtracting the zonal mean between $80^{\circ} \mathrm{W}$ and $0^{\circ}$ : a welldefined thermal dipole, stronger than any other anomaly in the range of longitudes selected, (represented by a warm anomaly between $800 \mathrm{hPa}$ and $400 \mathrm{hPa}$ and a cool anomaly between $825 \mathrm{hPa}$ and the surface) can be seen in correspondence to the dry tongue. Since the cross-section cuts across the SAL intrusion, it appears that temperature, in the core of the SAL, is up to $3^{\circ} C$ warmer than the surroundings at the same latitude. Most important, in the section there is also evidence of a thin dry air intrusion being entangled in the circulation at about $48^{\circ}-51^{\circ} \mathrm{W}$. This intrusion is not associated to a thermal dipole. A step-by-step streamline analysis compared with microwave geostationary imagery (not shown) show quite clearly that this is a fine intrusion of midlatitude air, produced by a large anticyclone in the Atlantic, dry because of subsidence. The GEOS-5 $0.25^{\circ}$ forecasts keep these 
two air masses well separate.

In Figure 7, for verification purposes, the same figure is extracted from the fullresolution NCEP operational analyses in model sigma levels $(0.5$ corresponding roughly to $500 \mathrm{hPa}$ ). Despite small-scale differences, the NCEP analysis confirms the thermal structure depicted in the GEOS-5 24-hour forecast and the presence of a very well-defined dry intrusion at about $35^{\circ}-40^{\circ} \mathrm{W}$. Most remarkable is the presence of a similar thermal dipole seen in Figure 3. A positive anomaly of up to about $3^{\circ} \mathrm{C}$, even stronger than the GEOS-5 forecast, is present in the mid-troposphere, and a corresponding cool anomaly in the low moist layer. Both anomalies are obtained, as in Figure 3, by subtracting the $80^{\circ} \mathrm{W}-0^{\circ}$ mean. This is in partial agreement with Dunion and Velden, (2004). The relatively new aspect of this analysis is that also a negative value appears in the moist low-level layer at the base of the column. Finally, it is important to notice that the thin midlatitude dry air intrusion, clearly seen in the GEOS-5 analyses and maintained in the 24hour GEOS-5 forecasts as a separate air mass (Figure 6), is not represented in the NCEP analyses (Figure 7), possibly being merged with the surrounding air mass.

\section{3c. Developing wave}

The Hovmøller computed in Figure 1 shows a strong wave moving from about $10^{\circ} \mathrm{W}$ to $40^{\circ} \mathrm{W}$ between $00 \mathrm{z} 10$ and 15 September (hereafter W2). Saharan Air precedes the wave: however, in contrast with $\mathrm{W} 1$, values of low humidity are less extended, suggesting that the SAL intrusion was not at strong. This is the wave that is associated with the system eventually named as Helene. 
In Figure 8, the GEOS-5 forecast for the genesis of Helene is shown. The $900 \mathrm{hPa}$ circulation shows a clearly defined vortex (at about $25^{\circ} \mathrm{W}$ and $12^{\circ} \mathrm{N}$ in the analyses) progressing westward and then recurving northwestward, being entangled in corresponding high levels of $700 \mathrm{hPa}$ moisture. The displacement error of the predicted center with respect to the observed position is smaller than $2^{o}$ at all times (not shown).

In Figure 9 a zonal cross-section at $13^{\circ} N$ (similarly to what was done to investigate W1 in Figure 6) is produced, intersecting both the center of the system W2 (which is a precursor of Hurricane Helene), and the SAL intrusion. The vertically aligned vorticity column at about $30^{\circ}-33^{\circ} \mathrm{W}$, stretching from the surface to the the tropopause, is the signature of the Tropical Storm, named Helene at 00z 14 September 2006 (Brown, 2006). A positive temperature anomaly of more than $2^{\circ}$ at about $35-45^{\circ} \mathrm{W}$ in the lower midtroposphere is associated with the same Saharan air outbreak which in the Hovmøller in Figure 1 reaches $40^{\circ} \mathrm{W}$ on 14 September. The anomalies seen within the vorticity column associated to Helene are not associated to the SAL but are due to the tropical storm development (a hint of a warm core above $500 \mathrm{hPa}$ and some cooling possibly due to rainfall evaporation in the lower levels).

Comparing this cross-section with the one relative to the nondeveloping W1 (Figure 6), two prominent differences can be seen: there is minimal cool anomaly in the lowest levels, and the dry air appears more diluted with less sharp horizontal gradients.

In Figure 10, for validation purposes, we plot the same vertical zonal cross- 
section seen in Figure 9, but this time from the full-resolution NCEP analyses in sigma levels. The vertical column of vorticity present at about $30^{\circ}-33^{\circ} \mathrm{W}$ is the analyzed signature of Tropical Storm Helene, and a warm anomaly of up to $3^{\circ} \mathrm{C}$ at about $40^{\circ}$, corresponding to the SAL intrusion, is also present in the midlower troposphere. Despite the much weaker NCEP representation of Helene with respect to the GEOS-5 (the latter being closer to observations since Helene at that time was already a named system) the NCEP and GEOS-5 systems agree well on the overall scenario of a SAL intrusion preceding Helene, but not as strong as the case seen in W1.

\section{Discussion}

\section{4a. Possible role of the $S A L$}

W1 and W2 do present some similarities: among them, vertical shear, computed as difference between the vertically integrated $100-200 \mathrm{hPa}$ and $800-900 \mathrm{hPa}$ wind speed, does not reach $10 \mathrm{~m} \mathrm{~s}^{-1}$. Other environmental conditions, such as sea surface temperature and low-level vorticity appear very favorable in both W1 and W2 case (not shown); however only the latter underwent development becoming Helene. The only difference appears to be the intensity of the Saharan Air intrusion depicted in analyses and GEOS-5 forecasts. In the model, the temperature dipole associated with the SAL affecting W1 can be followed at each time step and can be considered a possible cause of suppression (increasing static stability in the wave) together with the SAL dryness. In the precursor of Helene, while dry air being present especially on its northern and western quadrants, the low-level 
negative anomaly is minimal or absent, and therefore the effect on static stability is smaller.

The positive anomaly can be simply attributed to the signature of warm air originated over the Sahara but the cool anomaly in the lower levels does not have any plausible explanation relying on transport only. There is no source of localized cooler temperatures at that latitude, away from landmass and in a very homogeneous marine tropical environment. At this time a possible explanation is that the low-level cool temperatures are at least partly an indirect evidence of dust amount. The thermal effect of Saharan mineral dust is a net reduction of downwave shortwave radiation in the near-surface levels, and a heating in the lower midtroposphere, corresponding to the core of the SAL.

To support this possibility, we present in Fig. 11 the aerosol optical depth measured from the Moderate Resolution Imaging Spectroradiometer (MODIS) is compared between the periods of 26-29 August 2006 and 13-16 September 2006. These periods encompass the snapshots of the circulations in Figures 5 and 8. Notwithstanding some contamination of MODIS data by clouds, the air advected by the large-scale flow in W1 circulation, especially on its northern side, is likely to contain a larger amount of dust. The different amount of dust must have a different impact on the thermal structure of the atmosphere. It appears that the highresolution analyses and forecasts can represent these different thermal structures and that the GEOS-5 model initialized by such analyses can retain it for 24-72 hours advecting it into the circulation and producing a realistic cyclone dissipation. In the case of the GEOS-5 forecast, the nature of the finite-volume dynamics 
(Lin, 2004) is such that is a particularly suitable tool to generally maintain sharp gradients by minimizing unrealistic diffusion processes. The finite-volume dynamics has been shown to be very efficient in the mid latitudes where localized temperature gradients associated with sharp fronts can be very realistically simulated and maintained. This work documents that the same skill can be very useful also in the tropics when dealing with Saharan Air.

\section{4b. Critical role of data coverage and model resolution}

In this work, as stated in the introduction, two sets of forecasts were produced from the GEOS-5 high quality analyses, at resolution of half and a quarter of a degree. The most prominent result is that the forecasts issued at a half degree, when compared to the quarter degree, are not as suitable to retain all the information present in the analyses, and, especially with respect to the SAL, tend to irreparably blur the sharpness of its boundaries. Also the thermal information is sometimes diluted and spread unrealistically. To provide evidence of this problem, in Figure 11 shows the same section of Figure 6 (which was obtained from the 24-hour forecast at $0.25^{\circ}$ ) but from the corresponding forecast at $0.5^{\circ}$. The most prominent difference is that there the SAL filament is much broader and with less sharply-defined borders. Moreover, there is no clear separation between the midlatitude dry air at about $50^{\circ} \mathrm{W}$ and the $\mathrm{SAL}$ (at about $35^{\circ}-42^{\circ}$ ) as seen in Figure 6. In addition, the cool anomaly in the lower level is substantially less confined and spread in the lower resolution forecasts. Finally, Figure 6 shows a moist column at $25^{\circ}-30^{\circ} \mathrm{W}$ which is associated with $\mathrm{W} 1$; this feature is basically 
absent from the half degree forecast.

It is important to stress that it is not only the resolution of the model or of the data assimilation system which can suppress the fine structure of the SAL and its thermal properties. On data poor area, such as the Sahel and the eastern tropical Atlantic the optimal use of satellite information, far for being implemented in any operational system, is probably as important as the resolution.

One of the purposes of the GEOS-5 development was to contribute to the creation of a new set of analyses, the Modern Era Retrospective Analysis for Research and Applications (MERRA), documented by Bosilovich (2008) by making a much more extensive use of all satellite information. The GEOS-5 used in this work is almost the same version adopted for MERRA. The difference between the NCEP operational analyses and the GEOS-5 analyses (which are of comparable resolution) evident for example between Figures 9 and 10 in terms of sharpness of moisture boundaries, and the intensity of Helene, are probably due to the different assimilation of satellite data.

\section{Conclusion}

This work investigates AEW development during the the SOP-3 phase of the NAMMA campaign with the aid of the NASA GEOS-5 data assimilation and forecasting system. A data assimilation run is performed to produce a high quality set of global analyses which make heavy use of satellite information. From these improved analyses, two sets of 305 -day forecasts at two different resolution are produced. Forecasts are validated against operational NCEP analyses. 
A very strong non-developing wave is selected and is compared with the wave that eventually developed into Hurricane Helene. Analyses and forecasts document the presence of a strong temperature dipole associated with the Saharan air intrusion. This dipole is advected into the circulation of the wave, and may have contributed to inhibit further development by increasing static stability. No such dipole is found for the Saharan air that intruded in Helene's precursor. MODIS optical thickness show that the SAL outbreak of the first case contained a higher amount of dust. The lower tropospheric cooling associated with the strong Saharan air outbreak suggests that the high resolution global simulations and analyses can capture not only the SAL intrusion but also possibly part of the thermal effect consequent to downward shortwave reduction caused by large amounts of Saharan dust. When this thermal structure is well-represented in the initial conditions, a high-resolution global model can have more skill in predicting the impact of SAL on a tropical cyclone.

At this time, the role of dust on tropical cyclogenesis is still subject to a vigorous debate and contrasting evidence have been presented by Dunion and Velden (2004) in which a cyclogenesis suppression is suggested, and Jenkins et al. (2008) which provide evidence of rain band invigoration attributed to dust.

It is clear that the details of possible radiative effects by dust on cyclogenesis will have to be investigated by a high-resolution GCM with interactive dust aerosol. This capability is not yet available anywhere within the scientific community, but this work aims to provide a set of important needed requirements to even plan such research. 
In particular, we have emphasized how the resolution is a critical parameter in being able to represent with some degree of confidence the fine sharpness of SAL intrusions in tropical circulations. No simulation can be reasonably hope to investigate the complexity of the mechanisms involved with interaction of SAL and tropical cyclones at a resolution lower than a quarter of a degree. This is a demanding standard for global modeling but the evidence provided in this paper suggests that it is an inescapable necessity.

Second, in this work it is shown that even at the respectable resolution of the current operational analyses, inadequate use of satellite data, especially on data poor areas, may be a serious limitation. On the other hand, the density of satellite information adopted and, most important, the quality of the coverage, may bring substantial improvement to our understanding of processes associated to tropical cyclogenesis.

Acknowledgments Authors acknowledge support from Dr. Ramesh Kakar, NASA Headquarters, through the NAMMA Project, and use of NASA High-End Computing resources. 


\section{REFERENCES}

Asnani, G. C., 2005: Tropical Meteorology. Publisher: Indian Institute of Tropical Meteorology, Pashan, Pune-411008, India. 3 vols.

Atlas, R., O. Reale, B.-W. Shen, S.-J. Lin, J.-D. Chern, W. Putman, T. Lee, K.S. Yeh, M. Bosilovich, and J. Radakovich, 2005: Hurricane forecasting with the high-resolution NASA finite-volume general circulation model. Geophys. Res. Letters,32, L03807, doi:10.1029/2004GL021513.

Bosilovich, M. G., S.D. Schubert, M. Rienecker, R. Todling, M. Suarez, J. Bacmeister, R. Gelaro, G.-K. Kim, I. Stajner, and J. Chen, 2006: NASA's Modern Era Retrospective-analysis for Research and Applications. U.S. CLIVAR Variations, 4, (2,) 5-8.

—: NASA's Modern Era Retrospective-analysis for Research and Applications: Integrating Earth Observations. Earthzine. Available online at: http://www.earthzine.org/2008/09/26/nasas-modern-era-retrospective-analysis

Brown, D. P., 2006: Tropical Cyclone Report. Hurricane Helene (AL082006). 12-24 September 2006. Available online at http://www.nhc.noaa.gov/pdf/TCRAL082006_Helene.pdf

Burpee, R. W., 1974: Characteristics of north African Easterly waves during the summers of 1968 and 1969. J. Atmos. Sci, 31, 1556-1570.

Carlson, T. N., and J. M. Prospero, 1972: The large-scale movements of Saharan air outbreaks over the northern equatorial Atlantic. J. Appl. Meteorol., 11, 283-297. 
Dunion, J., and C. S. Velden, 2004: The impact of the Saharan Air Layer on Atlantic Tropical Cyclone activity. Bull. Am. Meteorol. Soc., 85, 353-365.

Hsieh, J.-S., and K. Cook, 2005: Generation of African Easterly Wave disturbances: Relationship to the African Easterly Jet. Mon. Wea. Rev. 133, 1311-1327.

Jenkins, G. S., A. Pratt, and A. Heymsfield, 2008: Possible linkages between Saharan dust and tropical cyclone rain band invigoration in the eastern Atlantic during NAMMA-06. Geophys. Res. Lett., 35, L08815, doi:10.1029/2008GL034072.

—, and —, 2008: Saharan dust, lightning and tropical cyclones in the eastern tropical Atlantic during NAMMA-06. Geophys. Res. Lett., 35, L12804, doi:10.1029/2008GL033979.

Kiladis, G. N., C. D. Thorncroft, and N. M. J. Hall (2006), Three-Dimensional Structure and Dynamics of African Easterly Waves. Part I:Observations, J. Atmos. Sci., 63, 2212-2230.

Lau, K. M. and K.-M. Kim, 2007: Cooling of the Atlantic by Saharan dust. Geophys. Res. Lett., 34, L23811, doi:10.1029/2007GL031538.

Lin, S.-J., 2004: A 'vertically lagrangian’ finite-volume dynamical core for global models, Mon. Wea. Rev., 132, 2293-2307.

Reale, O., J. Terry, M. Masutani, E. Andersson, L. P. Riishojgaard, J. C. Jusem, 2007: Preliminary evaluation of the European Centre for MediumRange Weather Forecasts (ECMWF) Nature Run over the Tropical At- 
lantic and African Monsoon region. Geophys. Res. Lett., 34, L22810, doi:10.1029/2007GL31640.

—, J. Susskind, R. Rosenberg, E. Brin, E. Liu, L. P. Riishojgaard, J. Terry, J. C. Jusem, 2008: Improving forecast skill by assimilation of qualitycontrolled AIRS temperature retrievals under partially cloudy conditions. Geophys. Res. Lett., 35, L08809, doi:10.1029/2007GL033002.

—, W. K. Lau, J. Susskind, E. Brin, E. Liu, L. P. Riishojgaard, M. Fuentes, R. Rosenberg, 2009: AIRS Impact on the Analysis and Forecast Track of Tropical Cyclone Nargis in a global data assimilation and forecasting system. Geophys. Res. Lett., in press.

Shen, B.-W., R. Atlas, O. Reale, S.-J. Lin, J.-D. Chern, J. Chang, C. Henze, and J.-L. Li, 2006: Hurricane forecasts with a global mesoscale-resolving model: Preliminary results with Hurricane Katrina (2005). Geophys. Res. Lett., 33, L13813, doi:10.1029/2006GL026143.

Susskind, J., C. Barnet, J. Blaisdell, L. Iredell, F. Keita, L. Kouvaris, G. Molnar, and M. Chahine, 2006: Accuracy of geophysical parameters derived from Atmospheric Infrared Sounder/Advanced Microwave Sounding Unit as a function of fractional cloud cover, J. Geophys. Res., 111, D09S17, doi:10.1029/2005JD006272.

—, 2007: Improved atmospheric soundings and error estimates from analysis of AIRS/AMSU data, Proc.of SPIE Vol. 6684, Atmospheric and Environmental Remote Sensing Data Processing and Utilization III: Readiness for 
GEOSS, San Diego, California, August 27-28, 2007.

Wu, W.-S., R.J. Purser and D.F. Parrish, 2002: Three-dimensional variational analysis with spatially inhomogeneous covariances, Mon. Wea. Rev., 130, 2905-2916. 


\section{List of Figures}

1 Hovmøller of $700 \mathrm{hPa}$ relative vorticity $\left(s^{-1}\right.$, left panel) and relative humidity (right panel) from the GEOS-5 operational analyses, latitudinally averaged $\left(12^{\circ}-20^{\circ} N\right)$, covering the SOP-3 period from 15 August to 15 September. . . . . . . . . . . . . . 26

2 Hovmøller of $700 \mathrm{hPa}$ relative vorticity $\left(s^{-1}\right.$, left panel) and relative humidity (right panel) from the NCEP operational analyses, latitudinally averaged $\left(12^{\circ}-20^{\circ} \mathrm{N}\right)$, covering the SOP-3 period from 15 August to 15 September. . . . . . . . . . . . . . . 27

3 Sequence of the observed profiles of the zonal (above) and meridional (below) components of the wind, taken daily at $12 \mathrm{Z}$ at the Cape Verde station (Latitude $14.926111^{\circ} \mathrm{N}$, Longitudie $23.494611^{\circ} \mathrm{W}$, and altitude $85 \mathrm{~m}$ ) during the SOP-3 campaign. . . . . . . . . . . . . . 28

4 Same as Figure 3, but extracted from the GEOS-5 analyses: sequence of the observed profiles (at each synoptic time) of the zonal (above) and meridional (below) components of the wind, taken at the same latitude and longitude of the sation. . . . . . . . . . . .

5 GEOS-5 (at $\left.0.25^{\circ}\right): 700 \mathrm{hPa}$ specific humidity $\left(g \mathrm{Kg}^{-1}\right)$ and $900 \mathrm{hPa}$ wind (streamlines) in the GEOS-5 analyses (upper left) for 00z $26 \mathrm{Au}$ gust, and relative to the 24, 48 and 72 hour forecasts for $00 \mathrm{z} 26,27$ and 28 August. . . . . . . . . . . . . . . . 30 
6 GEOS-5 (at $\left.0.25^{\circ}\right)$ : zonal vertical cross-section of specific humidity ( $g \mathrm{Kg}^{-1}$, shaded) and temperature anomaly $\left({ }^{\circ} \mathrm{C}\right.$, red/blue contour, positive/negative, subtracting the zonal mean between $80^{\circ} \mathrm{W}$ and $0^{\circ}$ ) at $20^{\circ} \mathrm{N}$ for $00 \mathrm{z} 27$ August, 24 hour forecast initialized at $00 \mathrm{z} 26$ August. W1 located at about $25-30^{\circ} \mathrm{W} \ldots \ldots \ldots 31$

7 As Figure 6, but extracted from NCEP full-resolution analyses in model levels for validation purpose: zonal vertical cross-section of specific humidity ( $g K g^{-1}$, shaded) and temperature anomaly $(\mathrm{C}$, red/blue contour, positive/negative, subtracting the zonal mean between $80^{\circ} \mathrm{W}$ and $0^{\circ}$ ) at $20^{\circ} \mathrm{N}$ for $00 \mathrm{z} 27$ August. W1 located at about $25-30^{\circ} \mathrm{W}$ The vertical dimension is only approximately comparable with Figure 3 since the spacing between model levels and pressure levels is different. . . . . . . 32

8 GEOS-5 (at $\left.0.25^{\circ}\right)$ : $700 \mathrm{hPa}$ specific humidity $\left(g \mathrm{Kg}^{-1}\right.$, shaded) and 900 $\mathrm{hPa}$ wind (streamlines) in the Analyses (upper left) for 00z 13 September, and relative to the 24,48 and 72 hour forecasts for $00 \mathrm{z} 14,15$ and 16 September. . . . . . . . . . . . . . 33

9 GEOS-5 (at $0.25^{\circ}$ ): zonal vertical cross-section of specific humidity ( $g \mathrm{Kg}^{-1}$, shaded), temperature anomaly $\left({ }^{\circ} \mathrm{C}\right.$, red/blue contour, positive/negative, subtracting the zonal mean between $80^{\circ} \mathrm{W}$ and $0^{\circ}$ ) and cyclonic vorticity (darker red, contours at $1,2,3 \times 10^{-4} \mathrm{~s}^{-1}$ at $20^{\circ} \mathrm{N}$ for $00 \mathrm{z} 14$ September, 24 hour forecast initialized at 00z 13 September. The developing TS Helene, identifiable by the vertical column of strong cyclonic vorticity, is located at about $32^{\circ} \mathrm{W} \ldots \ldots . . . . . . .34$ 
10 As Figure 9, but extracted from NCEP full-resolution analyses in model levels for validation purpose: zonal vertical cross-section of specific humidity ( $g K g^{-1}$, shaded), temperature anomaly $\left({ }^{\circ} C\right.$, red/blue contour, positive/negative, subtracting the zonal mean between $80^{\circ} \mathrm{W}$ and $0^{\circ}$ ) and cyclonic vorticity (darker red, contours at $1,2,3 \times 10^{-4} \mathrm{~s}^{-1}$ at $20^{\circ} \mathrm{N}$ for $00 \mathrm{z} 14$ September. The developing TS Helene, identifiable by the vertical column of strong cyclonic vorticity, is located at about $32^{\circ} \mathrm{W} . \quad$. 35

11 Four-day mean MODIS aerosol optical depth for (a) 26-29 August 2006 and (b) 13-16 September 2006. The MODIS data show much larger amount of dust for the first wave, which is the non-developing one. . . . 36

12 As Figure 6, but produced from GEOS-5 at the lower resolution of $0.5^{\circ}$ zonal vertical cross-section of specific humidity ( $g K^{-1}$, shaded) and temperature anomaly $\left({ }^{\circ} C\right.$, red/blue contour, positive/negative, subtracting the zonal mean between $80^{\circ} \mathrm{W}$ and $0^{\circ}$ ) at $20^{\circ} \mathrm{N}$ for $00 \mathrm{z} 27$ August, 24 hour forecast initialized at $00 \mathrm{z} 26$ August. . . . . . . . . . 37 


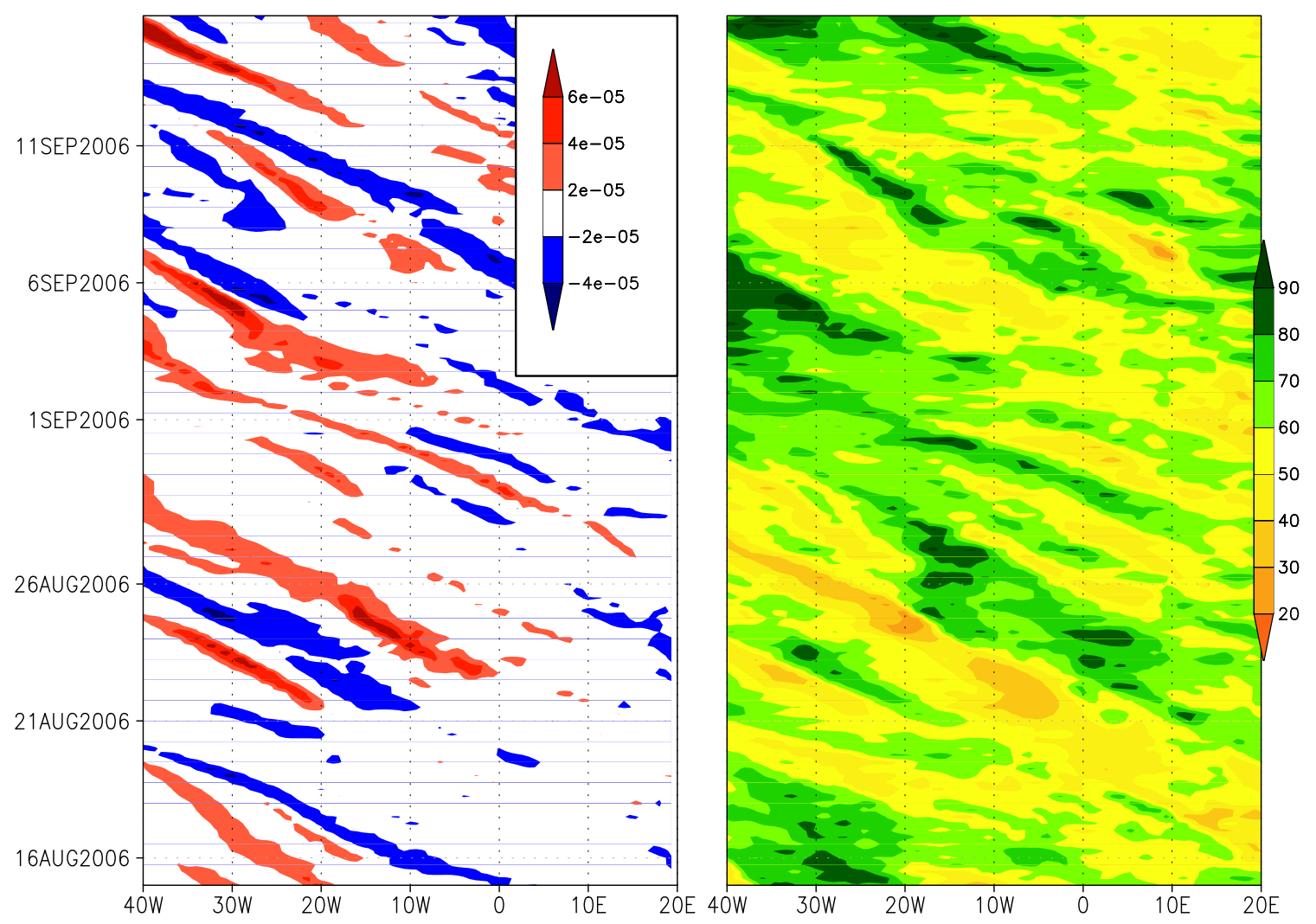

Figure 1: Hovmøller of $700 \mathrm{hPa}$ relative vorticity $\left(s^{-1}\right.$, left panel) and relative humidity (right panel) from the GEOS-5 operational analyses, latitudinally averaged $\left(12^{\circ}-20^{\circ} \mathrm{N}\right)$, covering the SOP-3 period from 15 August to 15 September. 


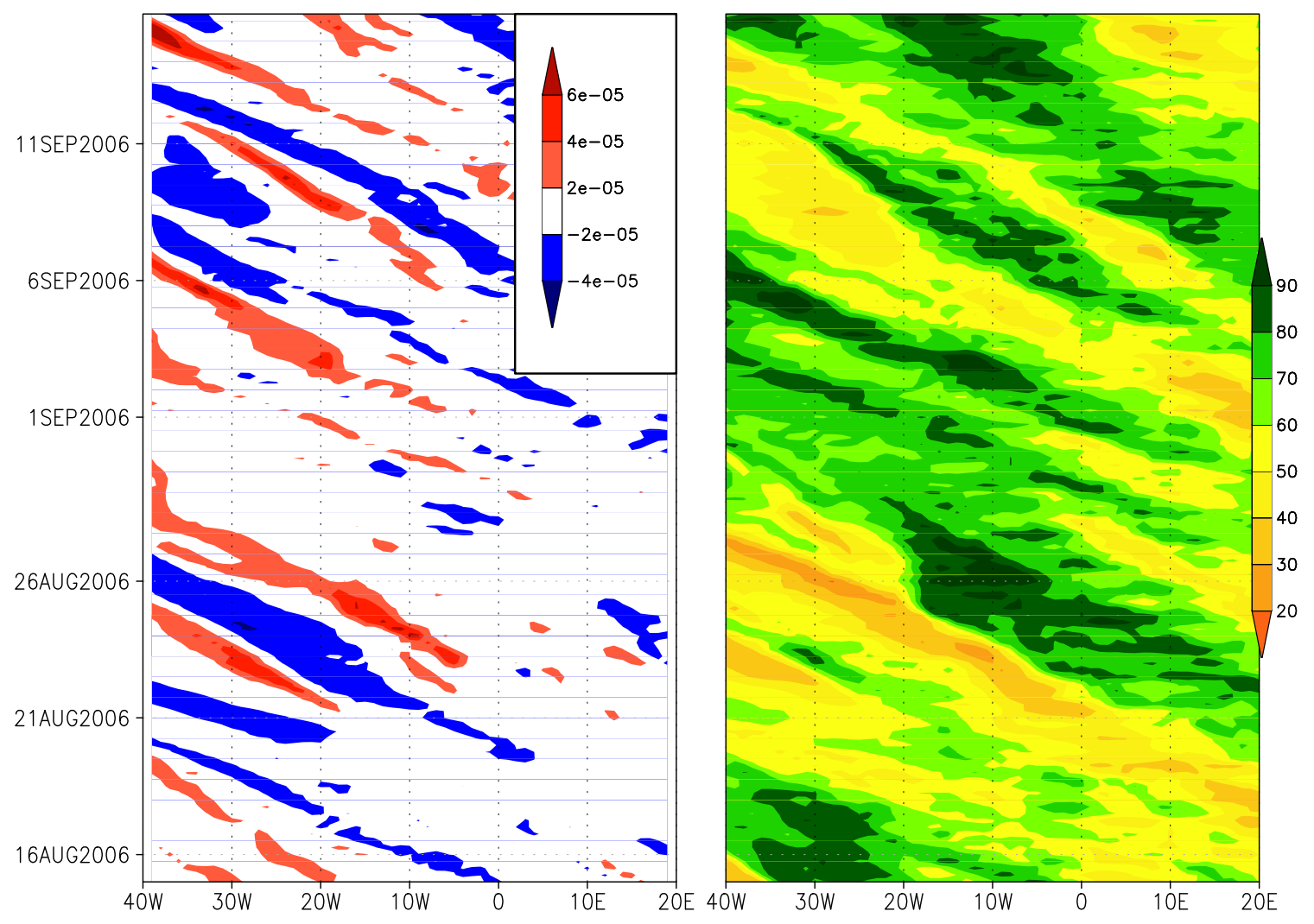

Figure 2: Hovmøller of $700 \mathrm{hPa}$ relative vorticity $\left(s^{-1}\right.$, left panel) and relative humidity (right panel) from the NCEP operational analyses, latitudinally averaged $\left(12^{\circ}-20^{\circ} \mathrm{N}\right)$, covering the SOP-3 period from 15 August to 15 September. 

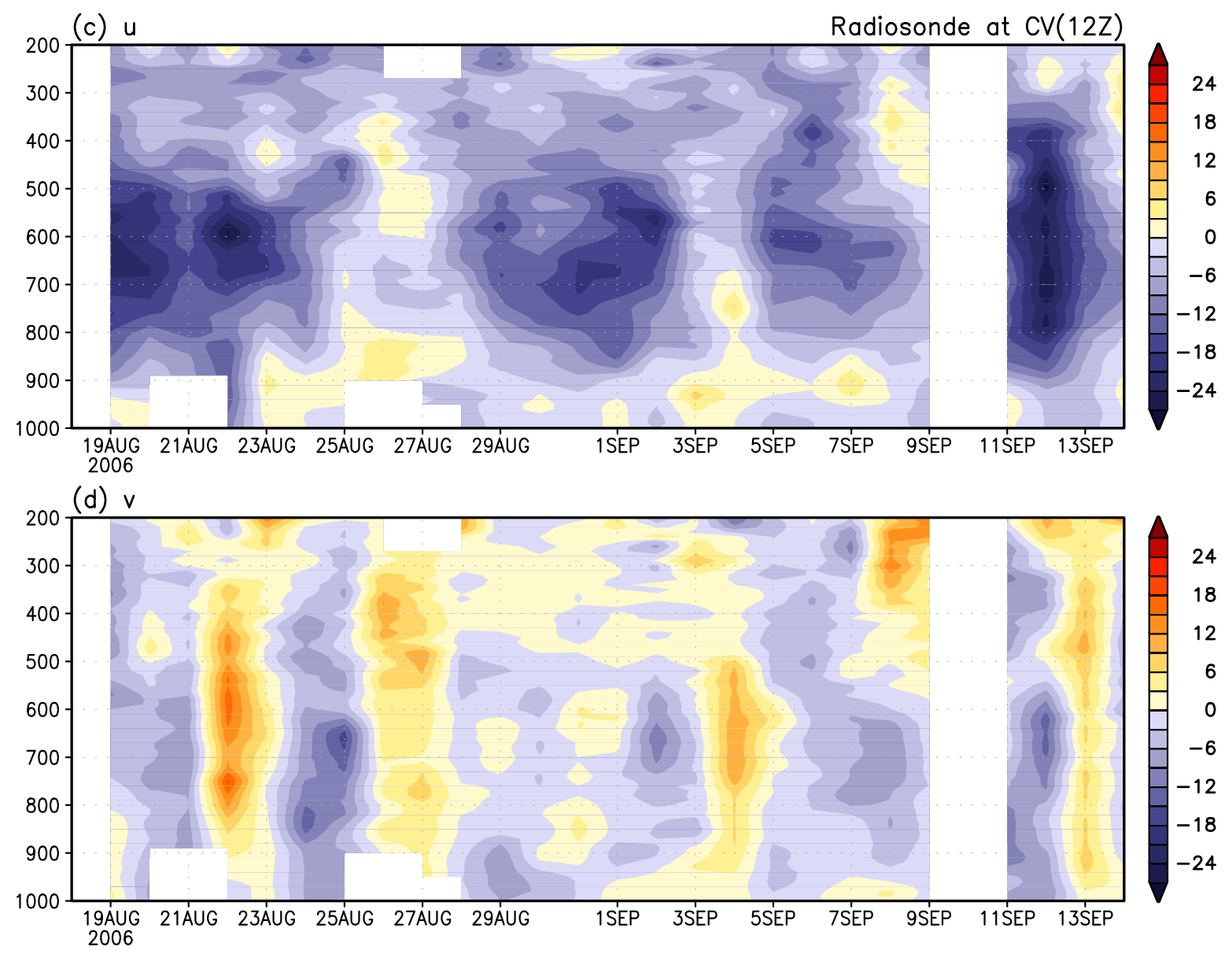

Figure 3: Sequence of the observed profiles of the zonal (above) and meridional (below) components of the wind, taken daily at $12 \mathrm{Z}$ at the Cape Verde station (Latitude $14.926111^{\circ} \mathrm{N}$, Longitudie $23.494611^{\circ} \mathrm{W}$, and altitude $85 \mathrm{~m}$ ) during the SOP-3 campaign. 

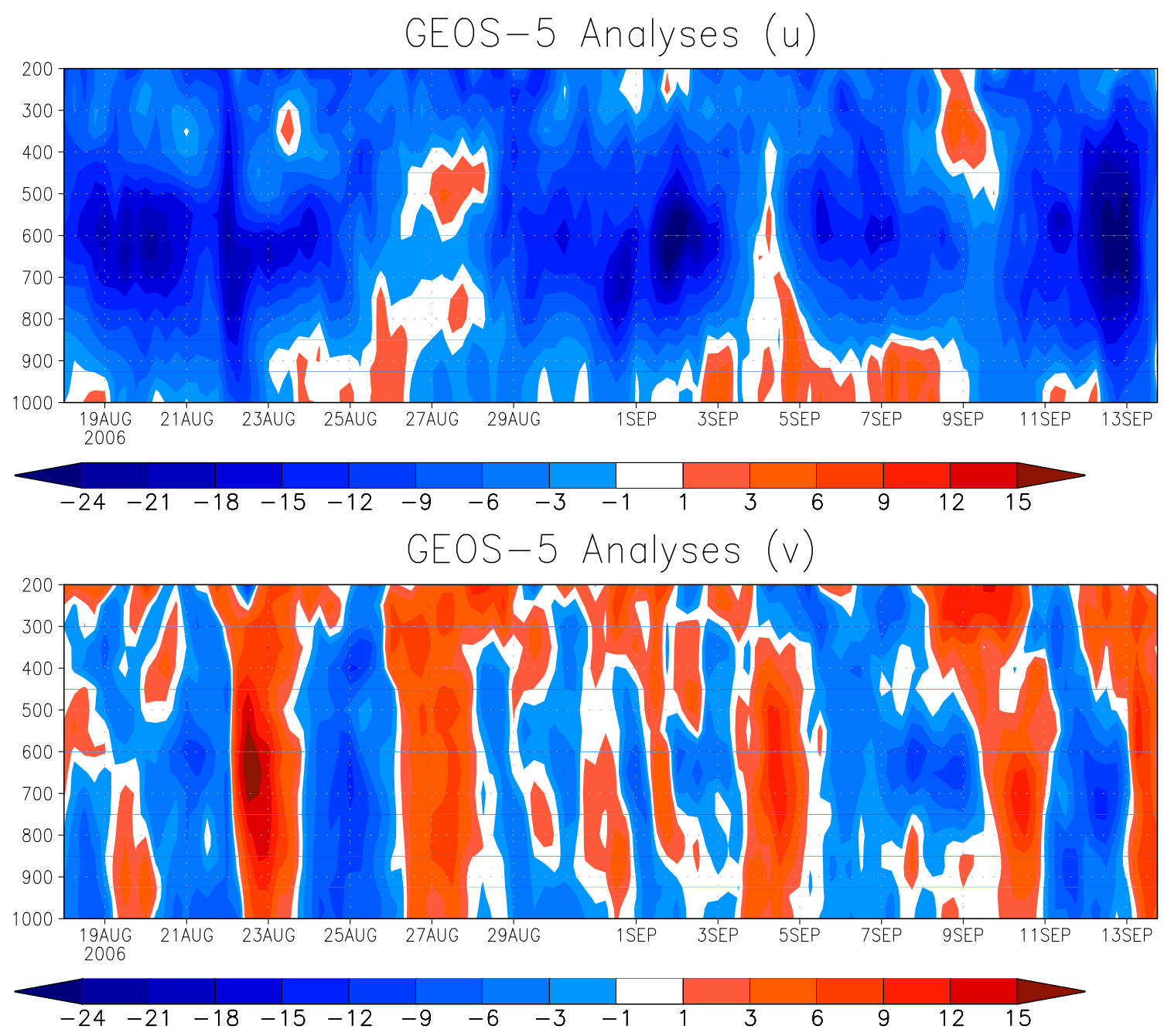

Figure 4: Same as Figure 3, but extracted from the GEOS-5 analyses: sequence of the observed profiles (at each synoptic time) of the zonal (above) and meridional (below) components of the wind, taken at the same latitude and longitude of the sation. 

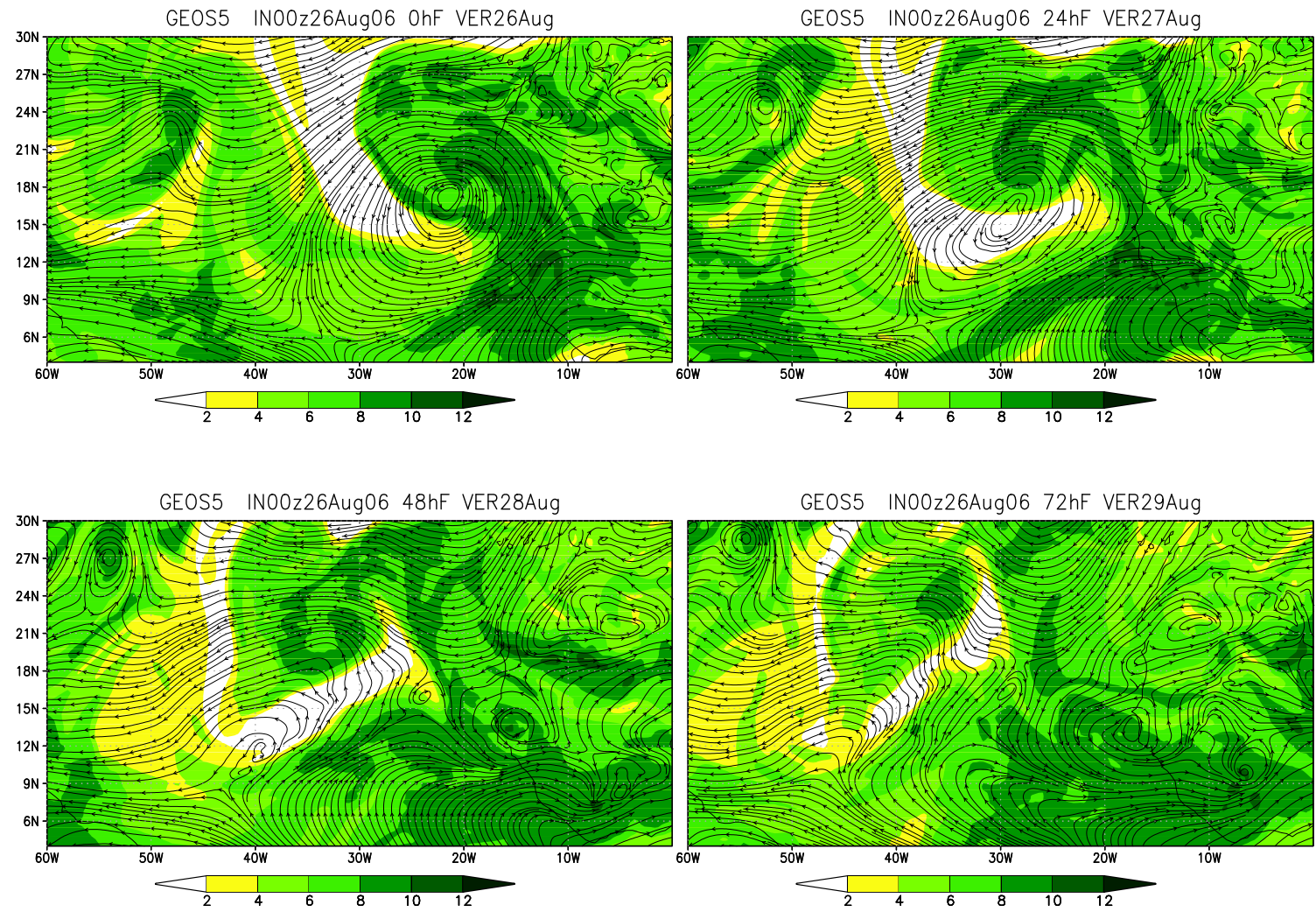

Figure 5: GEOS-5 (at $\left.0.25^{\circ}\right)$ : $700 \mathrm{hPa}$ specific humidity $\left(\mathrm{g} \mathrm{Kg}^{-1}\right)$ and $900 \mathrm{hPa}$ wind (streamlines) in the GEOS-5 analyses (upper left) for 00z 26 August, and relative to the 24, 48 and 72 hour forecasts for 00z 26, 27 and 28 August. 


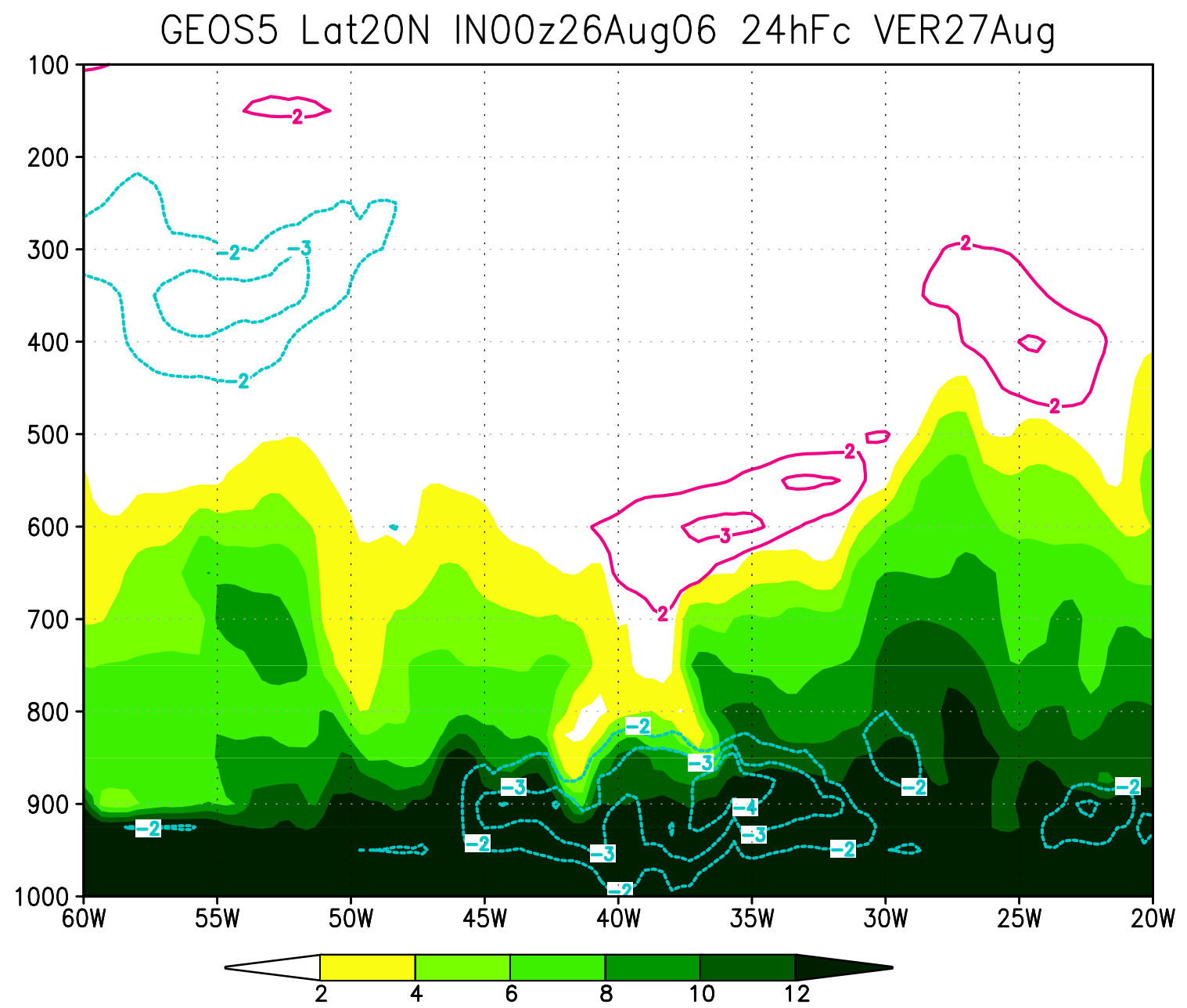

Figure 6: GEOS-5 (at $0.25^{\circ}$ ): zonal vertical cross-section of specific humidity $\left(g \mathrm{Kg}^{-1}\right.$, shaded) and temperature anomaly $\left({ }^{\circ} C\right.$, red/blue contour, positive/negative, subtracting the zonal mean between $80^{\circ} \mathrm{W}$ and $0^{\circ}$ ) at $20^{\circ} \mathrm{N}$ for $00 \mathrm{z} 27$ August, 24 hour forecast initialized at $00 \mathrm{z} 26$ August. W1 located at about $25-30^{\circ} \mathrm{W}$. 


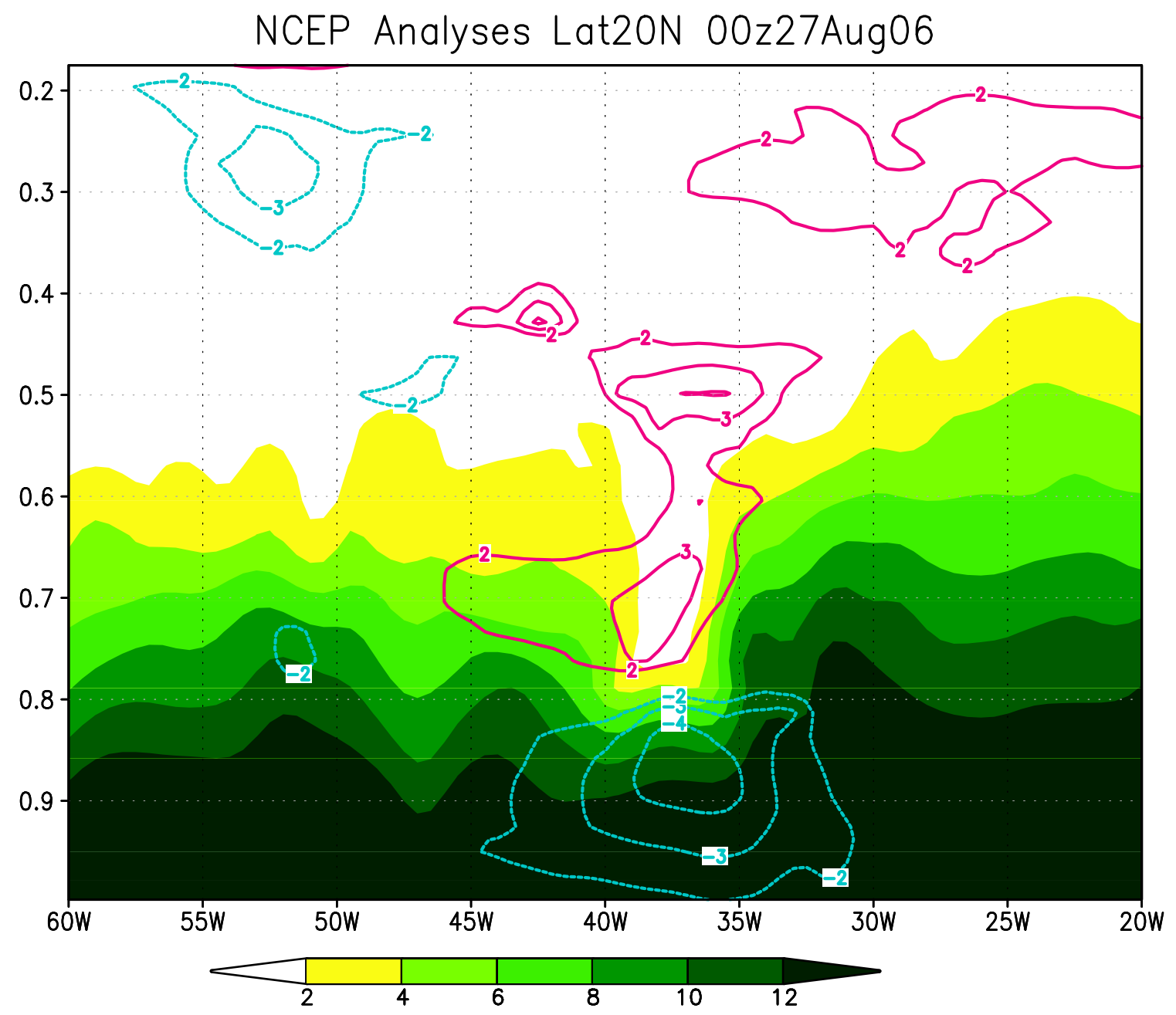

Figure 7: As Figure 6, but extracted from NCEP full-resolution analyses in model levels for validation purpose: zonal vertical cross-section of specific humidity $\left(g \mathrm{Kg}^{-1}\right.$, shaded) and temperature anomaly $(\mathrm{C}$, red/blue contour, positive/negative, subtracting the zonal mean between $80^{\circ} \mathrm{W}$ and $0^{\circ}$ ) at $20^{\circ} \mathrm{N}$ for $00 \mathrm{z} 27$ August. W1 located at about $25-30^{\circ} \mathrm{W}$ The vertical dimension is only approximately comparable with Figure 3 since the spacing between model levels and pressure levels is different. 

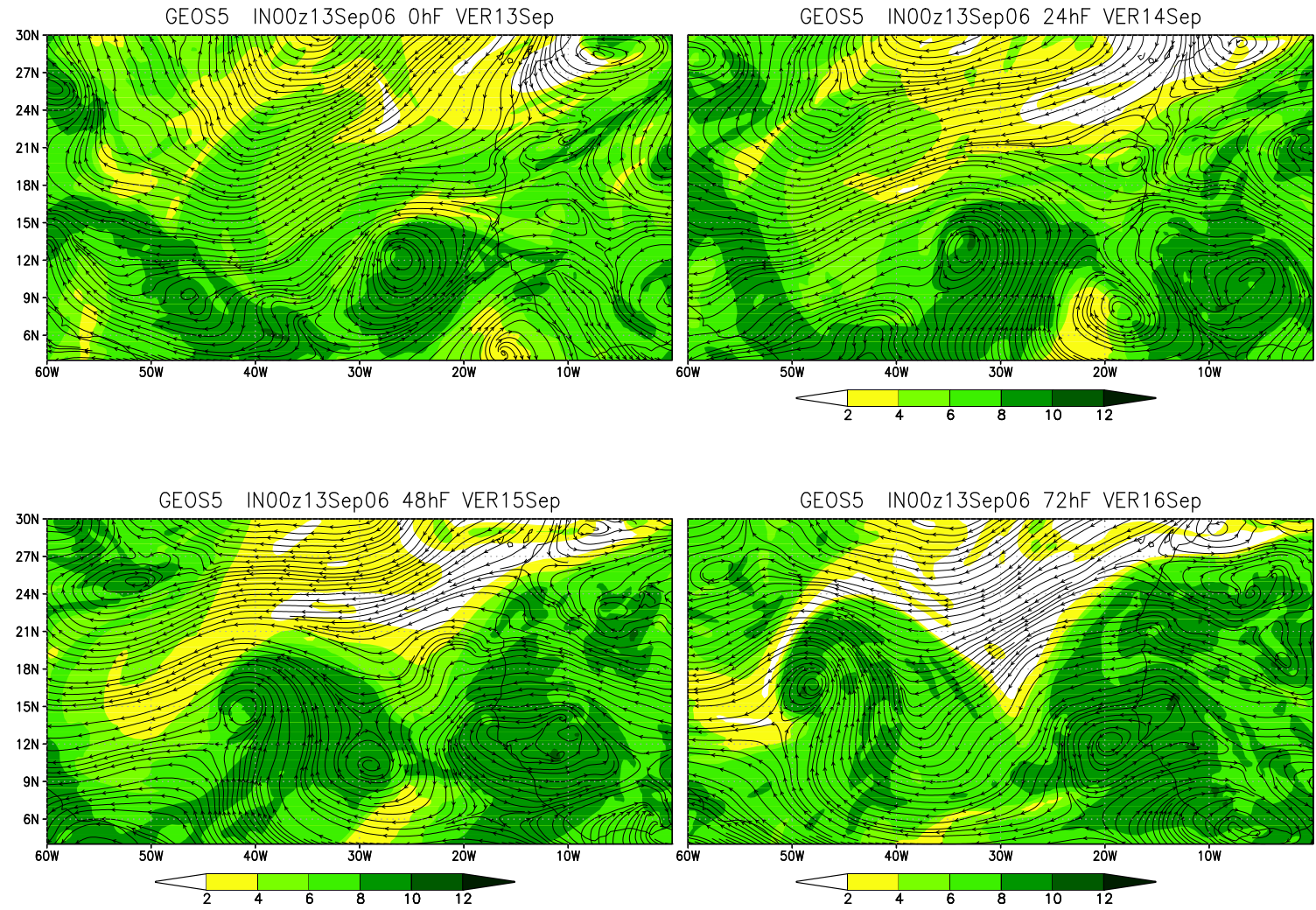

Figure 8: GEOS-5 (at $\left.0.25^{\circ}\right): 700 \mathrm{hPa}$ specific humidity $\left(g \mathrm{Kg}^{-1}\right.$, shaded) and $900 \mathrm{hPa}$ wind (streamlines) in the Analyses (upper left) for 00z 13 September, and relative to the 24, 48 and 72 hour forecasts for $00 \mathrm{z} 14,15$ and 16 September. 


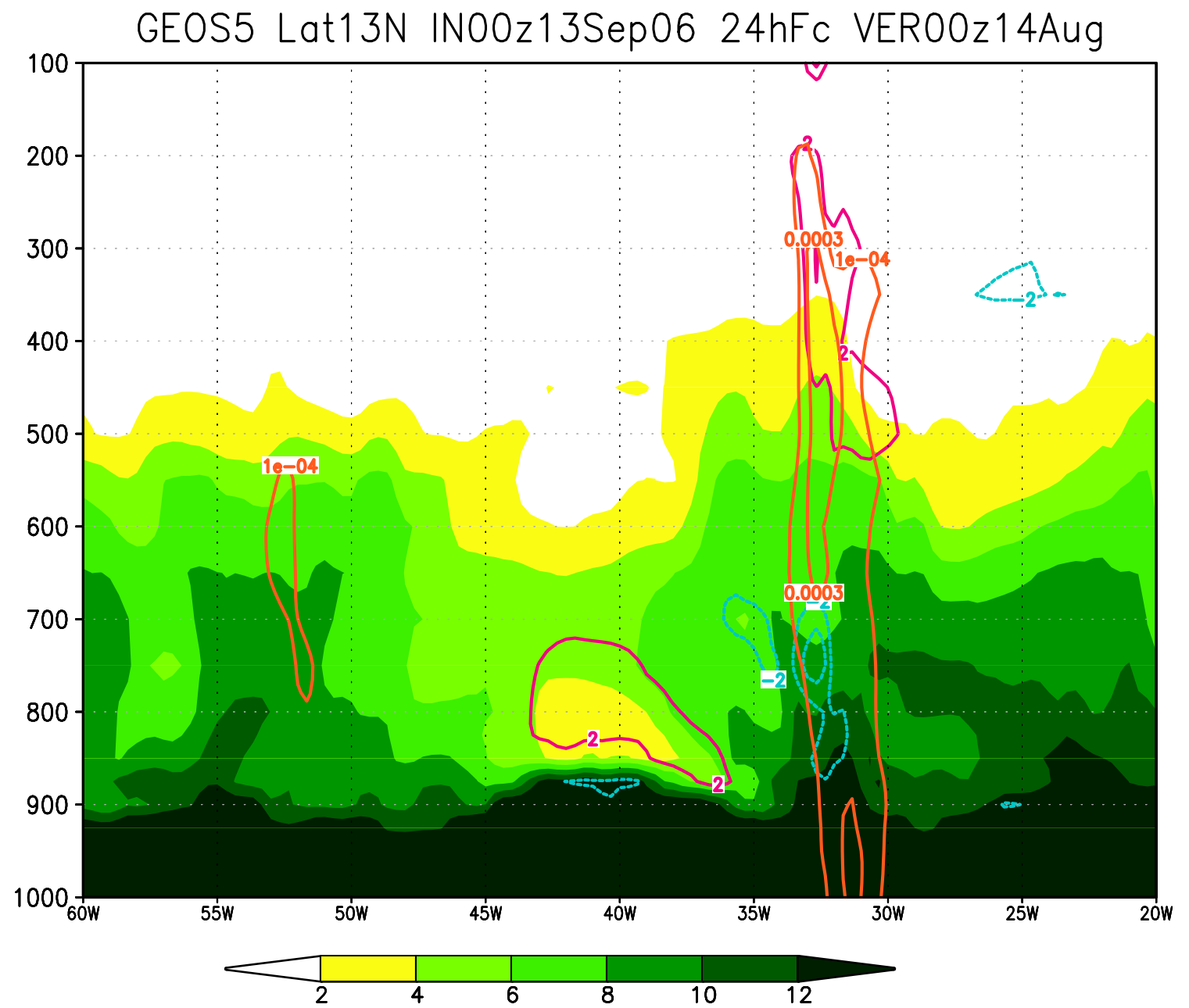

Figure 9: GEOS-5 (at $0.25^{\circ}$ ): zonal vertical cross-section of specific humidity ( $g \mathrm{Kg}^{-1}$, shaded), temperature anomaly $\left({ }^{\circ} C\right.$, red/blue contour, positive/negative, subtracting the zonal mean between $80^{\circ} \mathrm{W}$ and $0^{\circ}$ ) and cyclonic vorticity (darker red, contours at $1,2,3 \times$ $10^{-4} s^{-1}$ at $20^{\circ} N$ for $00 \mathrm{z} 14$ September, 24 hour forecast initialized at $00 \mathrm{z} 13$ September. The developing TS Helene, identifiable by the vertical column of strong cyclonic vorticity, is located at about $32^{\circ} \mathrm{W}$. 


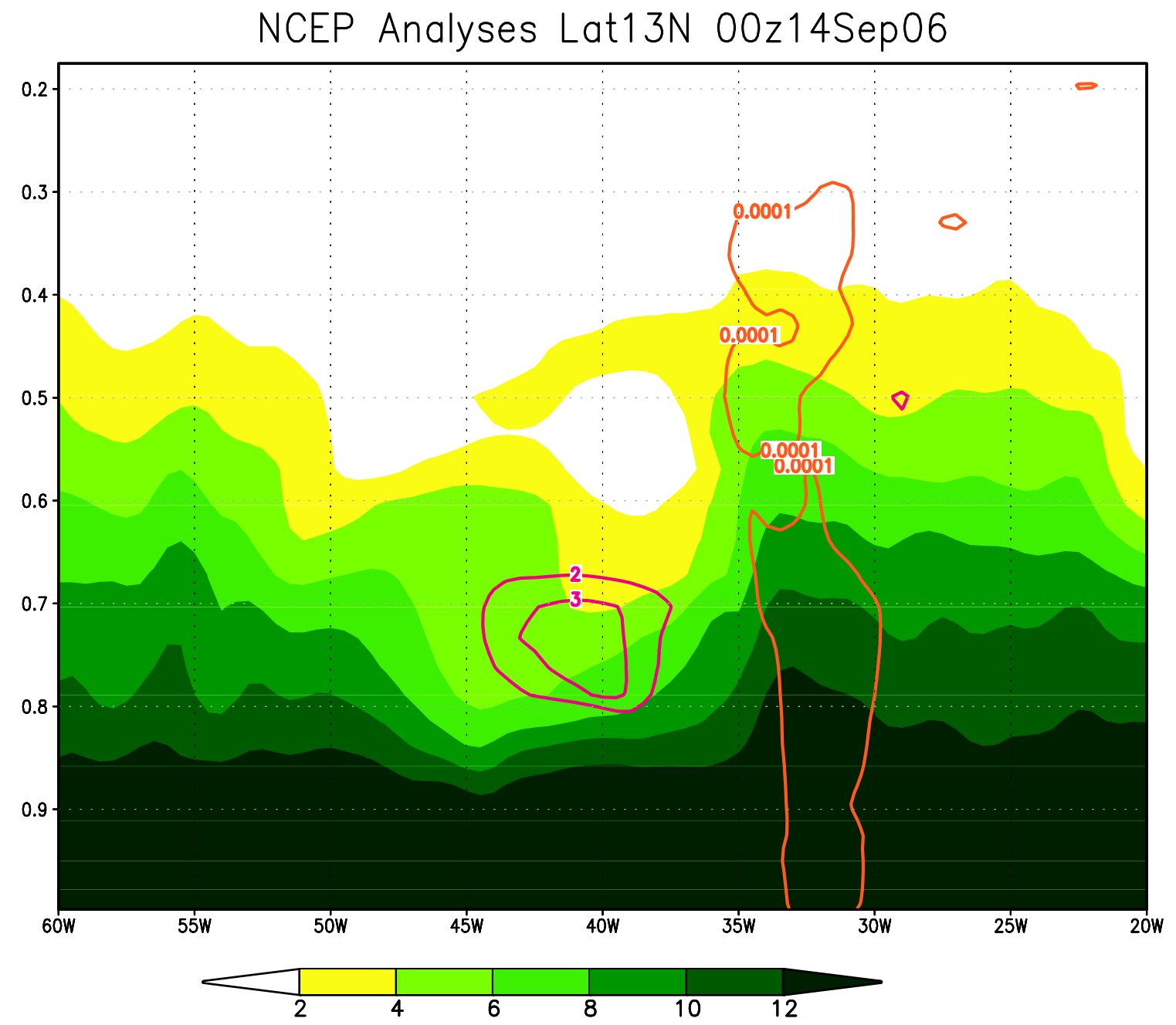

Figure 10: As Figure 9, but extracted from NCEP full-resolution analyses in model levels for validation purpose: zonal vertical cross-section of specific humidity $\left(g \mathrm{Kg}^{-1}\right.$, shaded), temperature anomaly $\left({ }^{\circ} \mathrm{C}\right.$, red/blue contour, positive/negative, subtracting the zonal mean between $80^{\circ} \mathrm{W}$ and $0^{\circ}$ ) and cyclonic vorticity (darker red, contours at $1,2,3 \times 10^{-4} \mathrm{~s}^{-1}$ at $20^{\circ} \mathrm{N}$ for $00 \mathrm{z} 14$ September. The developing TS Helene, identifiable by the vertical column of strong cyclonic vorticity, is located at about $32^{\circ} \mathrm{W}$. 


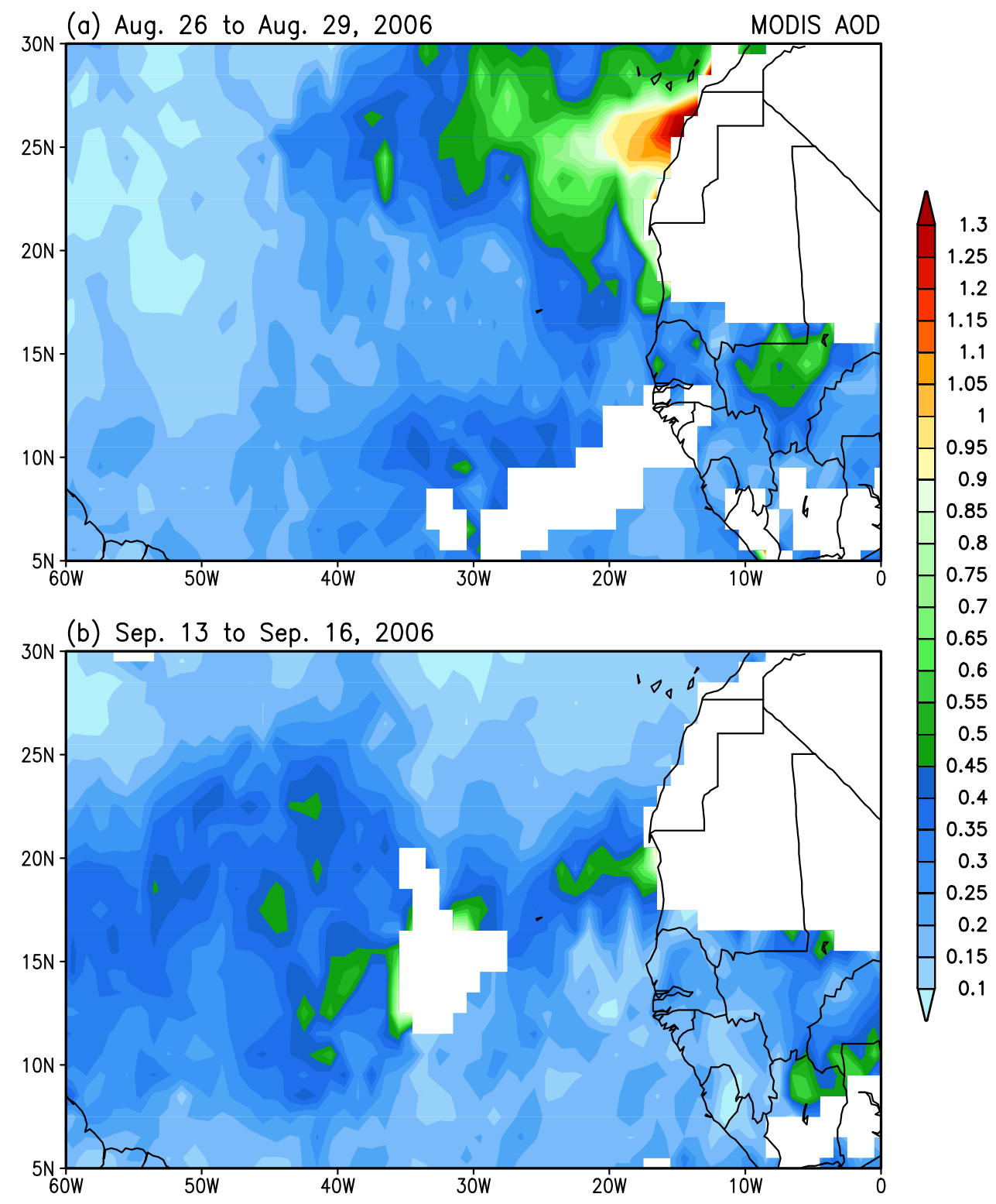

Figure 11: Four-day mean MODIS aerosol optical depth for (a) 26-29 August 2006 and (b) 13-16 September 2006. The MODIS data show much larger amount of dust for the first wave, which is the non-developing one. 


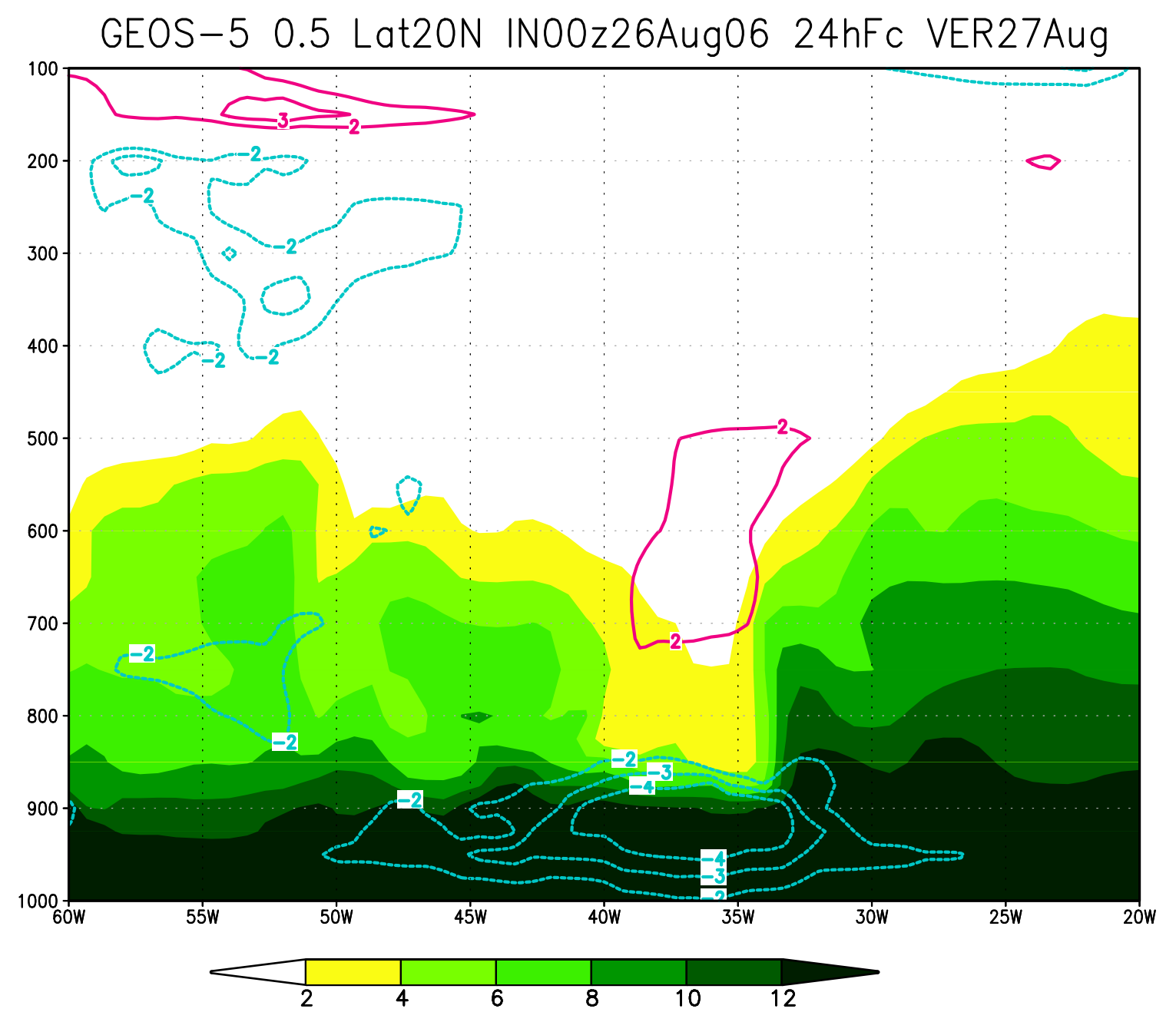

Figure 12: As Figure 6, but produced from GEOS-5 at the lower resolution of $0.5^{\circ}$ zonal vertical cross-section of specific humidity $\left(\mathrm{g} \mathrm{Kg}^{-1}\right.$, shaded) and temperature anomaly $\left({ }^{\circ} \mathrm{C}\right.$, red/blue contour, positive/negative, subtracting the zonal mean between $80^{\circ} \mathrm{W}$ and $0^{\circ}$ ) at $20^{\circ} N$ for $00 \mathrm{z} 27$ August, 24 hour forecast initialized at $00 \mathrm{z} 26$ August. 